\title{
Safety and Efficacy of Baricitinib Through 128 Weeks in an Open-label, Longterm Extension Study in Patients with Rheumatoid Arthritis
}

\author{
Edward C. Keystone, Mark C. Genovese, Douglas E. Schlichting, Inmaculada de la Torre, \\ Scott D. Beattie, Terence P. Rooney, and Peter C. Taylor
}

\begin{abstract}
Objective. To assess the safety and efficacy of baricitinib in patients with rheumatoid arthritis (RA) up to 128 weeks in a phase IIb study (NCT01185353).

Methods. After a 24-week blinded period, eligible patients entered an initial 52-week open-label extension (OLE); patients receiving $8 \mathrm{mg}$ once daily (QD) continued with that dose and all others received $4 \mathrm{mg}$ QD. Doses could be escalated to $8 \mathrm{mg}$ QD at 28 or 32 weeks at investigator discretion when $\geq 6$ tender and $\geq 6$ swollen joints were present. Patients completing the first OLE were eligible to enter a second 52-week OLE and receive $4 \mathrm{mg}$ QD regardless of previous dose.

Results. In the 4-mg $(\mathrm{n}=108)$ and 8 -mg $(\mathrm{n}=93)$ groups, treatment-emergent adverse events (AE) occurred in $63 \%$ and $67 \%$, serious AE in $16 \%$ and $13 \%$, infections in $35 \%$ and $40 \%$, and serious infections in $5 \%$ and $3 \%$ of patients, respectively. Exposure-adjusted incidence rates for AE for all baricitinib groups in the second OLE were similar to or lower than rates observed in the first OLE. No opportunistic infections, tuberculosis cases, or lymphomas were observed through 128 weeks; 1 death occurred during the first OLE. Among all patients in both OLE, the proportions who achieved disease improvement at Week 24 were similar or increased at weeks 76 and 128.

Conclusion. In a phase IIb study in RA, the safety and tolerability profile of baricitinib, up to 128 weeks, remained consistent with earlier observations, without unexpected late signals. Clinical improvements seen in the 24-week blinded period were maintained during the OLE. (First Release August 15 2017; J Rheumatol 2018;45;14-21; doi:10.3899/jrheum.161161)
\end{abstract}

\section{Key Indexing Terms: RHEUMATOID ARTHRITIS SAFETY}

\section{BARICITINIB LONGTERM}

\section{CLINICAL EFFICACY PHASE II}

From the Rebecca MacDonald Centre for Arthritis and Autoimmune Diseases, Mount Sinai Hospital, Toronto, Ontario, Canada; Division of Immunology and Rheumatology, Stanford University School of Medicine, Palo Alto, California; Eli Lilly and Company, Indianapolis, Indiana, USA; Kennedy Institute of Rheumatology and Nuffield Department of Orthopaedics, Rheumatology and Musculoskeletal Sciences, University of Oxford, Oxford, UK.

The study was funded by Eli Lilly and Company and Incyte Corp. ECK has received grants/research support or consulting support from Amgen, Eli Lilly and Company, Merck, Pfizer, and Sandoz. MCG has received grants/research support or consulting support from Eli Lilly and Company. DES, SDB, I. de la T, and TPR are employees of, and own stock or stock options in, Eli Lilly and Company. PCT has received grants/research support or consulting support from Eli Lilly and Company.

E.C. Keystone, MD, The Rebecca MacDonald Centre for Arthritis and Autoimmune Diseases, Mount Sinai Hospital; M.C. Genovese, MD, Division of Immunology and Rheumatology, Stanford University School of Medicine; D.E. Schlichting, RN, PhD, Eli Lilly and Company; I. de la Torre, MD, PhD, Eli Lilly and Company; S.D. Beattie, PhD, Eli Lilly and Company; T.P. Rooney, MD, Eli Lilly and Company; P.C. Taylor, MA, PhD, FRCP, FRCPE, Kennedy Institute of Rheumatology and Nuffield Department of Orthopaedics, Rheumatology and Musculoskeletal Sciences, University of Oxford.

Address correspondence to Dr. E.C. Keystone, The Rebecca MacDonald Centre for Arthritis and Autoimmune Diseases, Mount Sinai Hospital, 60 Murray St., Room 2-006, Box 4, Toronto, Ontario M5T 3L9, Canada. E-mail:Ed.Keystone@sinaihealthsystem.ca

Full Release Article. For details see Reprints and Permissions at jrheum.org Accepted for publication June 3, 2017.
Rheumatoid arthritis (RA) is an inflammatory polyarthropathy. Several proinflammatory cytokines including interleukin 6 (IL-6), IL-12, IL-23, interferon, granulocytemacrophage colony-stimulating factor, and the $\gamma$ chain cytokines including IL-2 use the Janus kinase (JAK) intracellular signaling pathway and have been associated with RA. Several small-molecule JAK inhibitors are in clinical development, each having a particular selectivity for inhibition of 1 or more of the 4 enzymes within the JAK family ${ }^{1}$.

Baricitinib is an oral, selective, JAK1/JAK2 inhibitor ${ }^{2}$. In a phase IIa study in patients with active RA despite treatment with disease-modifying antirheumatic drugs (DMARD), baricitinib [4, 7, or $10 \mathrm{mg}$ administered once daily (QD)] improved the signs and symptoms of RA after 12 weeks of treatment compared to placebo, with no unacceptable safety finding $\mathrm{s}^{3}$. In a phase IIb double-blind study conducted in Japanese patients, QD baricitinib was also associated with significant improvement in RA disease activity compared to placebo at the primary 12 -week timepoint ${ }^{4}$. In a larger, phase IIb, double-blind, randomized, placebo-controlled, dose-ranging study in patients with active RA despite treatment with methotrexate $(\mathrm{MTX}) \pm$ other conventional synthetic DMARD, significantly more patients in the 
combined baricitinib 4- and 8-mg QD groups compared to placebo achieved the American College of Rheumatology $20 \%$ response (ACR20) primary endpoint at Week $12(76 \%$ vs $41 \%, \mathrm{p}<0.001)^{5}$. Significant improvement was also observed across ACR50, ACR70, Disease Activity Score for 28-joint count (DAS28), Clinical Disease Activity Index (CDAI), and Simplified Disease Activity Index (SDAI); baricitinib was well-tolerated with no unexpected safety findings through Week 24. Patients completing 24 weeks of treatment had the opportunity to receive up to 104 weeks of additional treatment with baricitinib as part of open-label extensions (OLE). Here we report details of safety data collected during these OLE and that clinical improvements observed at Week 24 were maintained or improved through Week 128.

\section{MATERIALS AND METHODS}

Study patients. Eligible patients met the inclusion criteria for the phase IIb study (clinicaltrials.gov NCT01185353) as described ${ }^{5}$. Briefly, patients aged 18 to 75 years with a diagnosis of adult-onset RA for at least 6 months and $<15$ years were eligible for inclusion in the study. Regular use of MTX for $\geq 12$ weeks and treatment at a stable dose of 10 to $25 \mathrm{mg} /$ week for $\geq 8$ weeks before baseline were required. Concurrent treatment with stable doses of hydroxychloroquine $(\leq 400 \mathrm{mg} /$ day $)$, sulfasalazine $(\leq 3000 \mathrm{mg} /$ day $)$, nonsteroidal antiinflammatory drugs, and oral corticosteroids $(\leq 10 \mathrm{mg} /$ day of prednisone or equivalent) was permitted. Patients were screened for latent tuberculosis and could enter the study if they completed a course of appropriate therapy. Patients who completed the double-blind period of the study were eligible for the OLE if they were at an investigative site that participated in the OLE.

Study design. In the double-blind period, patients were randomized 2:1:1:1:1 to placebo or $1,2,4$, or $8 \mathrm{mg}$ baricitinib QD for 12 weeks ${ }^{5}$. At 12 weeks, patients assigned to 2,4 , or $8 \mathrm{mg}$ continued assigned treatment and patients assigned to placebo or $1 \mathrm{mg}$ were reassigned to $4 \mathrm{mg}$ QD or $2 \mathrm{mg}$ twice daily (BID) for an additional 12 weeks of blinded treatment (weeks 12-24; Supplementary Figure 1A, available with the online version of this article). Patients completing Week 24 either were seen for followup 28 days after the last dose of baricitinib or entered a 52-week OLE (weeks 24-76; Supplementary Figure 1B, available with the online version of this article). In this first OLE, patients in the 8-mg group continued to receive $8 \mathrm{mg}$ QD. All other patients received $4 \mathrm{mg}$ QD, but could be escalated to $8 \mathrm{mg}$ QD at 28 or 32 weeks at the investigator's discretion when $\geq 6$ tender and $\geq 6$ swollen joints were present. Patients completing Week 76 either were seen for followup 28 days after the last dose of baricitinib or entered a second 52-week OLE (weeks 76-128), in which all patients received $4 \mathrm{mg}$ QD regardless of previous dose (Supplementary Figure 1B, available with the online version of this article). Data were available from the 24-week blinded period when the second OLE was being planned and designed. These data indicated that the 8-mg QD dose was associated with more laboratory abnormalities than the 4-mg QD dose, without producing additional efficacy. Therefore, the 8-mg QD dose was not included in the second OLE. Patients completing Week 128 were seen for followup 28 days after the last dose of baricitinib, or at participating centers they could proceed to a separate, additional longterm extension study (NCT01885078).

The study was designed by the sponsor, Eli Lilly and Company, an academic advisory board that included non-Lilly authors of this manuscript, and Incyte Corp. The study was conducted in accordance with ethical principles of the Declaration of Helsinki and Good Clinical Practice guidelines and was approved by the Schulman Institutional Review Board (\#10-5255-0). Ethics approval was also obtained for all 69 sites. All patients provided written informed consent.
Safety assessments. Safety was monitored throughout the OLE. Assessments included treatment-emergent adverse events (TEAE), serious AE (SAE; including deaths), discontinuations due to $\mathrm{AE}$, and clinical laboratory test abnormalities. The National Institutes of Health Common Terminology Criteria for Adverse Events Version 4.0 was used to describe categorical post-baseline laboratory changes. The protocol required that $\mathrm{AE}$ of herpes zoster or herpes simplex infection should lead to permanent discontinuation of study drug and that $\mathrm{AE}$ or laboratory abnormalities leading to permanent discontinuation should be designated as SAE. The SAE rates reported here include these protocol-defined SAE and SAE defined by conventional International Conference on Harmonisation criteria (death, inpatient hospitalization, life-threatening experience, persistent or significant disability/incapacity, congenital anomaly/birth defect, or considered significant by the investigator for any other reason).

Efficacy measures. Measures of efficacy recorded through Week 128 included ACR20, ACR50, ACR70, and DAS28 - based on the level of high-sensitivity C-reactive protein (DAS28-CRP) or erythrocyte sedimentation rate (DAS28-ESR) - both continuous and categorical $(\leq 3.2$ and $<2.6$ ) versions. Other measures were CDAI (continuous version and $\leq 2.8$ as remission), SDAI (continuous version and $\leq 3.3$ as remission), and ACR/European League Against Rheumatism (EULAR) Boolean remission. Each patient's functional ability was assessed by the Health Assessment Questionnaire-Disability Index (HAQ-DI), which is included in the ACR core set.

Statistical methods. Statistical analyses for the double-blind period of the study have been described ${ }^{5}$. Patients were grouped by 3 primary treatment experiences in the 2 OLE: those who were treated with $4 \mathrm{mg}$ baricitinib throughout (denoted as $4 \mathrm{mg}$ for the first OLE and $4 / 4 \mathrm{mg}$ for the second OLE), those who continued their assigned course of $8 \mathrm{mg}$ during weeks 24-76 and then decreased to the protocol-mandated $4 \mathrm{mg}$ for weeks $76-128$ (first OLE: $8 \mathrm{mg}$; second OLE: $8 / 4 \mathrm{mg}$ ), and those who began the first OLE on $4 \mathrm{mg}$, increased to $8 \mathrm{mg}$ through Week 76 , and then returned to the 4-mg dose through Week 128 (first OLE: 4:8 mg; second OLE: 4:8/4 mg). Because these were partially nonrandomized groups, statistical analyses were handled descriptively, without formal comparisons. For efficacy, changes from baseline and measures of treatment response were assessed relative to the original study randomization. Nonresponder imputation (NRI) was applied for all categorical measures: patients who discontinued prematurely were deemed to be nonresponders at all subsequent timepoints within each OLE. Continuous efficacy measures were summarized by last observation carried forward (LOCF) within each OLE. TEAE and SAE summaries included exposure-adjusted incidence rates, calculated as the number of patients with the designated event per 100 patient-years of observation time.

\section{RESULTS}

Patient baseline demographics and clinical characteristics. At the time of entry into the OLE, patient demographics were similar to each other and to those obtained from all patients at study entry, and measures of disease activity had decreased with treatment when compared to study entry (Table 1).

Patient disposition. Of the 301 initially randomized patients, $259(86 \%)$ completed the 24-week double-blind treatment period (Supplementary Figure 2, available with the online version of this article). Of these, 201 entered the first 52-week OLE (99\% of those completing the double-blind period at sites participating in the OLE), with 32 (16\%) discontinuing prior to Week 76 [12 (6\%) because of an AE, $2(1 \%)$ for lack of efficacy] and $169(84 \%)$ completing the OLE (Figure 1). Of these, 144 patients entered the second OLE ( $96 \%$ of those completing the first OLE at sites participating in the second).

Personal non-commercial use only. The Journal of Rheumatology Copyright $\subset$ 2018. All rights reserved. 
Table 1. Baseline characteristics and disease activity at Week 0, Week 24 and Week 76. Data are reported as mean values \pm SD unless otherwise indicated

\begin{tabular}{|c|c|c|c|}
\hline Characteristics & $\begin{array}{c}\text { Week } 0 \\
\text { All Groups, } \\
\mathrm{n}=301\end{array}$ & $\begin{array}{c}\text { Week } 24 \\
\text { All Groups, } \\
\text { n = } 201\end{array}$ & $\begin{array}{c}\text { Week } 76 \\
\text { All Groups, } \\
\text { n = } 144\end{array}$ \\
\hline Age, yrs & $51 \pm 12$ & $51 \pm 12$ & $53 \pm 11$ \\
\hline Female, \% & 83 & 83 & 83 \\
\hline Duration of RA, yrs & $5.6 \pm 4.4$ & $5.9 \pm 4.5$ & $5.9 \pm 4.4$ \\
\hline ACPA-positive ${ }^{\mathrm{a}}, \%$ & 69 & 67 & 69 \\
\hline RF-positive ${ }^{\mathrm{b}}, \%$ & 71 & 70 & 74 \\
\hline Prednisone use, $\%$ & 49 & 51 & 46 \\
\hline \multicolumn{4}{|l|}{ Background DMARD use } \\
\hline MTX monotherapy, \% & 69 & 79 & 75 \\
\hline MTX + other DMARD, \% & 29 & 20 & 24 \\
\hline Tender joints, of 68 & $22 \pm 12$ & $7 \pm 9$ & $6 \pm 8$ \\
\hline Swollen joints, of 66 & $16 \pm 8$ & $5 \pm 6$ & $4 \pm 4$ \\
\hline HAQ-DI ${ }^{\mathrm{c}}$ & $1.16 \pm 0.67$ & $0.78 \pm 0.64$ & $0.74 \pm 0.63$ \\
\hline High-sensitivity $\mathrm{CRP}^{\mathrm{d}}, \mathrm{mg} / \mathrm{l}$ & $13 \pm 19$ & $6 \pm 12$ & $5 \pm 12$ \\
\hline $\mathrm{ESR}, \mathrm{mm} / \mathrm{h}$ & $39 \pm 18$ & $27 \pm 19$ & $26 \pm 18$ \\
\hline DAS28-CRP & $5.5 \pm 0.9$ & $3.3 \pm 1.2$ & $2.9 \pm 1.2$ \\
\hline DAS28-ESR & $6.3 \pm 0.8$ & $4.0 \pm 1.3$ & $3.6 \pm 1.3$ \\
\hline CDAI & $37 \pm 12$ & $14 \pm 11$ & $11 \pm 9$ \\
\hline SDAI & $39 \pm 12$ & $15 \pm 11$ & $11 \pm 9$ \\
\hline
\end{tabular}

${ }^{a} A C P A$ positivity $(\mathrm{ULN}=5 \mathrm{U} / \mathrm{ml}) .{ }^{\mathrm{b}} \mathrm{RF}$ positivity $(\mathrm{ULN}=14 \mathrm{IU} / \mathrm{ml}) .{ }^{\mathrm{c}} \mathrm{Scores}$ on the HAQ-DI range from 0 to 3, with higher scores indicating greater disability. ${ }^{\mathrm{d}}$ High-sensitivity C-reactive protein (ULN $\left.=3 \mathrm{mg} / \mathrm{l}\right)$. ACPA: anticyclic citrullinated peptide antibody; CDAI: Clinical Disease Activity Index; CRP: C-reactive protein; DAS28-CRP: Disease Activity Score for 28 joints based on the CRP level; DAS28-ESR: DAS for 28 joints based on the erythrocyte sedimentation rate; DMARD: disease-modifying antirheumatic drugs; HAQ-DI: Health Assessment Questionnaire-Disability Index; MTX: methotrexate; RA: rheumatoid arthritis; RF: rheumatoid factor; SDAI: Simplified Disease Activity Index; ULN: upper limit of normal.

Eleven of them (8\%) discontinued prior to Week 128: $3(2 \%)$ because of an $\mathrm{AE}$ and none for lack of efficacy. There were 133 patients $(92 \%)$ who completed the final visit of the study treatment period (Figure 1).

Safety. The total exposure time to baricitinib in patients receiving at least 1 dose of the active drug during the study (including the initial 0-24 weeks) was 433.9 patient-years: 10.8 at $1 \mathrm{mg}$ QD, 23.7 at $2 \mathrm{mg}$ QD, 14.2 at $2 \mathrm{mg}$ BID, 284.5 at $4 \mathrm{mg} \mathrm{QD}$, and 100.7 at $8 \mathrm{mg}$ QD.

Overview of AE. Results are summarized separately in Table 2 for each dose studied during the OLE periods (4 mg QD and $8 \mathrm{mg} \mathrm{QD}$ ). For context, safety data from the 24-week blinded period are also presented for patients randomized to these doses. In addition, data from the 0 - to 24-week period are also presented for patients randomized to $2 \mathrm{mg}$ QD, because this dose was advanced, along with the 4-mg QD dose, for further evaluation in phase III studies. A detailed summary of selected SAE rates is presented in Supplementary Table 1, available with the online version of this article. Most patients experienced at least 1 TEAE during the study (Table 2). In general, no pronounced differences in the incidence of $\mathrm{AE}$ were seen between the doses studied, although for patients rescued during the first OLE, exposure-adjusted rates after Week 24 but prior to rescue (while receiving $4 \mathrm{mg}$ prior to $8 \mathrm{mg}$ QD) were difficult to interpret because of the brevity of this 4- to 8-week exposure period. Importantly, TEAE occurrence did not increase in frequency with prolonged exposure, and the lowest event rates were generally seen during the second OLE.

$\mathrm{AE}$ leading to discontinuation were seen infrequently (Table 2). Thirteen patients discontinued because of an $\mathrm{AE}$ during weeks 24-76 [1 anemia, 2 elevated transaminase, 1 increased creatine phosphokinase (CPK), and 4 herpes zoster in the 4-mg group; 1 basal cell carcinoma (BCC) of the skin and 1 herpes simplex in the 4/8-mg group; 1 colitis, 1 acute hepatitis B, and 1 fatal myocardial infarction in the $8-\mathrm{mg}$ group]. Other than the single uncomplicated BCC, no malignancies were reported during the study. Although a causative link was not established, the patient who acquired acute viral hepatitis reported this TEAE shortly after an invasive dental procedure. The diagnosis of myocardial infarction was made presumptively in a 68-year-old woman who died suddenly during this study period. No deaths were otherwise reported during the study. During the second OLE, 3 additional patients discontinued because of an $\mathrm{AE}$ ( 1 herpes simplex in the 4/4-mg group, and 1 anemia due to suspected gastrointestinal bleeding and 1 herpes zoster in the 4:8/4-mg group).

Among TEAE, the most commonly represented system organ class was infections and infestations (Table 2), although no increases in infections or serious infections were seen over time. Among cases of herpes zoster, no visceral or disseminated cases were reported, and the incidence rate for patients receiving at least one 4-mg dose during the study was 2.5/100 patient-years. Opportunistic infections or cases of tuberculosis were not seen during the study.

Laboratory results. Table 3 displays mean change from each OLE baseline $( \pm$ SD) for selected laboratory analytes. Mean neutrophil count decreased during the double-blind period with greater declines in the 8-mg dose group. Small increases in mean neutrophil count were observed in the first OLE with small decreases in the second OLE, in particular in patients decreasing from $8 \mathrm{mg}$ to $4 \mathrm{mg}$ QD. Three patients experienced a Grade 3 neutropenia, and no patient experienced a Grade 4 neutropenia or discontinued because of neutropenia in the entire study (Table 4). No significant change in mean lymphocyte count was observed during the double-blind period or in either OLE (Table 3). Two patients experienced Grade 3 abnormalities, and no patient experienced a Grade 4 abnormality or discontinued the study because of lymphopenia (Table 4). Mean platelet counts increased following baricitinib treatment in a dose-dependent manner during the double-blind period, with small changes in the first and second OLE reflecting changes in baricitinib dose from $4 \mathrm{mg}$ to $8 \mathrm{mg}$ and from $8 \mathrm{mg}$ to $4 \mathrm{mg}$ QD in the first and second OLE, respectively (Table 3). Protocol-defined thrombo-

Personal non-commercial use only. The Journal of Rheumatology Copyright @ 2018 . All rights reserved. 


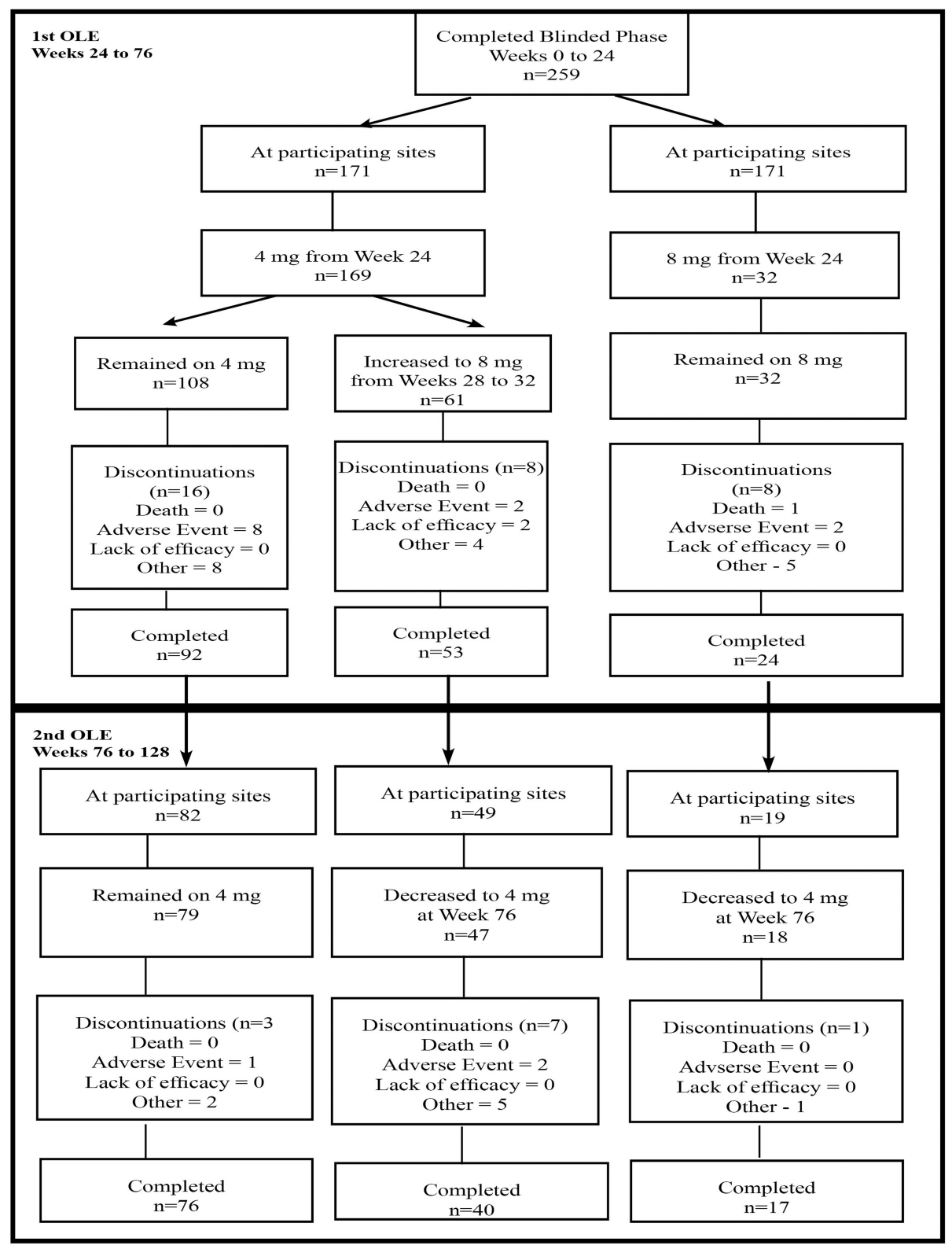

Figure 1. Patient disposition, weeks 24-128. Reasons for discontinuation include adverse event, lack of efficacy, investigator decision, protocol violation, entry criteria not met, and patient decision. One hundred patients did not enter the first open-label extension (OLE): 42 patients who discontinued during the double-blind period (weeks 0-24) and 58 patients who completed Week 24. Of the 58 eligible patients who did not enter the first OLE, 55 were from sites not participating in the OLE and 3 elected not to participate. Fifty-seven patients did not continue to the second OLE: 32 who discontinued during the first OLE and 25 who completed the first OLE (19 patients from sites not participating in the second OLE and 6 who elected not to participate).

cytosis occurred in very few patients (Table 4). A mean decline in hemoglobin was observed in the 8-mg group, consistent with a higher percentage of Grade 1 abnormalities $(\geq 10.0 \mathrm{~g} / \mathrm{dl}$ to below lower limit of normal) during the 24-week blinded period (Table 3 and Table 4). No clinically significant change in mean hemoglobin occurred during the OLE. Mean alanine aminotransferase (ALT) did not change in a clinically meaningful amount in the double-blind period or either OLE. Mean ALT increased in the 8-mg dose group during the first OLE. This reflected 1 patient (described above) with acute hepatitis B and reporting very high ALT; median change $(-0.5 \mathrm{IU} / \mathrm{l})$ did not indicate a general increase within this group. During the first OLE, low-density lipoprotein cholesterol increased less than in the 24-week 
Table 2. Safety summary for weeks 0-24, weeks 24-76, and weeks 76-128. Data are n (\%) [IR].

\begin{tabular}{|c|c|c|c|c|c|c|c|c|c|c|}
\hline & \multicolumn{3}{|c|}{$\begin{array}{l}\text { Blinded Period, Weeks 0-24 } \\
\text { Randomized Dose }\end{array}$} & \multirow[b]{2}{*}{$4 \mathrm{mg}$} & \multicolumn{3}{|c|}{$\begin{array}{l}\text { First OLE, Weeks } 24-76 \\
\text { (4 mg or } 8 \mathrm{mg}) \\
4: 8 \mathrm{mg}\end{array}$} & \multicolumn{3}{|c|}{$\begin{array}{l}\text { Second OLE, Weeks 76-128 } \\
\text { (4 mg throughout) }\end{array}$} \\
\hline & $2 \mathrm{mg}$ & $4 \mathrm{mg}$ & $8 \mathrm{mg}$ & & Pre-rescue & Post-rescue & $8 \mathrm{mg}$ & $4 / 4 \mathrm{mg}$ & $4: 8 / 4 \mathrm{mg}$ & $8 / 4 \mathrm{mg}$ \\
\hline & $\begin{array}{c}\mathrm{n}=52, \\
\mathrm{PYE}=23.6\end{array}$ & $\begin{array}{c}\mathrm{n}=52, \\
\mathrm{PYE}=23.2\end{array}$ & $\begin{array}{c}\mathrm{n}=50 \\
\mathrm{PYE}=22.4\end{array}$ & $\begin{array}{c}\mathrm{n}=108 \\
\mathrm{PYE}=102.8\end{array}$ & $\begin{array}{c}n=61 \\
\operatorname{PYE}=6.1\end{array}$ & $\begin{array}{c}\mathrm{n}=61, \\
\mathrm{PYE}=50.7\end{array}$ & $\begin{array}{c}\mathrm{n}=32, \\
\mathrm{PYE}=27.5\end{array}$ & $\begin{array}{c}\mathrm{n}=79 \\
\mathrm{PYE}=78.1\end{array}$ & $\begin{array}{c}n=47 \\
\mathrm{PYE}=43.0\end{array}$ & $\begin{array}{c}\mathrm{n}=18 \\
\mathrm{PYE}=17.3\end{array}$ \\
\hline SAE & $3(6)[12.7]$ & 0 & $4(8)$ [17.7] & $17(16)[16.5]$ & $1(2)[16.5]$ & $6(10)[11.8]$ & $6(19)[21.8]$ & $5(6)[6.4]$ & $3(6)[7.0]$ & 0 \\
\hline due to $\mathrm{AE}$ & $1(2)[4.2]$ & $1(2)[4.3]$ & 1 (2) [4.4] & 8 (7) [7.8] & $1(2)[16.5]$ & 1 (2) [2.0] & $3(9)$ [10.9] & $1(1)[1.3]$ & $2(4)[4.7]$ & 0 \\
\hline Infections & $14(27)[59.4]$ & $13(25)[56.3]$ & $14(28)[61.8]$ & $38(35)[37.0]$ & $8(13)$ [131.7] & $25(41)$ [49.3] & $12(38)[43.6]$ & $24(30)[30.7]$ & $13(28)[30.3]$ & $5(28)[28.9]$ \\
\hline Herpes zoster* & 0 & 0 & 0 & $6(6)[5.8]$ & 0 & $1(2)[2.0]$ & $2(6)[7.3]$ & $1(1)[1.3]$ & 0 & 0 \\
\hline Serious infections & $2(4)[8.5]$ & 0 & $1(2)[4.4]$ & $5(5)[4.9]$ & $1(2)[16.5]$ & $1(2)[2.0]$ & $2(6)[7.3]$ & $2(3)[2.6]$ & $2(4)[4.7]$ & 0 \\
\hline
\end{tabular}

4/4 mg = $4 \mathrm{mg}$ baricitinib for weeks 24-76 and weeks 76-128. 4:8/4 = $4 \mathrm{mg}$ baricitinib through Week 28 or 32, then $8 \mathrm{mg}$ through Week 76 and $4 \mathrm{mg}$ for weeks 76-128. 8/4 mg = $8 \mathrm{mg}$ baricitinib for weeks 24-76 and $4 \mathrm{mg}$ for weeks 76-128. Pre-rescue includes all AE that began or worsened on or before the date of dose escalation. Post-rescue includes all AE that began or worsened after the date of dose escalation. * Among the cases of herpes zoster, 5 patients were receiving concomitant steroid and 5 patients were not receiving concomitant steroid. IR: incidence rate; AE: adverse event; OLE: open-label extension; PYE: patient-years of exposure; n: no. patients treated with stated dose regimen in the study period or no. patients with event; TEAE: treatment-emergent AE; SAE: serious AE.

Table 3. Change from each OLE baseline for selected laboratory analytes. Data represented as mean change from baseline \pm SD. Baseline in the blinded period is Week 0, baseline in the first OLE is Week 24, and baseline in the second OLE is Week 76.

\begin{tabular}{|c|c|c|c|c|c|c|c|c|c|c|}
\hline & $2 \mathrm{mg}, \mathrm{n}=52$ & $4 \mathrm{mg}, \mathrm{n}=52$ & $8 \mathrm{mg}, \mathrm{n}=50$ & $4 \mathrm{mg}, \mathrm{n}=108$ & $\begin{array}{c}\text { Pre-rescue, } \\
\mathrm{n}=61\end{array}$ & $\begin{array}{c}\text { Post-rescue } \\
n=61\end{array}$ & $8 \mathrm{mg}, \mathrm{n}=32$ & $\begin{array}{c}4 / 4 \mathrm{mg} \\
\mathrm{n}=79\end{array}$ & $\begin{array}{c}4: 8 / 4 \mathrm{mg} \\
\mathrm{n}=47\end{array}$ & $\begin{array}{c}8 / 4 \mathrm{mg} \\
\mathrm{n}=18\end{array}$ \\
\hline $\begin{array}{l}\text { Neutrophil count, } \\
10^{3} \text { cells } / \mathrm{mm}^{3}\end{array}$ & $-0.25 \pm 2.18$ & $-0.21 \pm 2.02$ & $-1.37 \pm 2.33$ & $0.32 \pm 2.09$ & $0.11 \pm 1.70$ & $0.29 \pm 2.08$ & $0.83 \pm 2.06$ & $-0.03 \pm 1.59$ & $-0.42 \pm 1.94$ & $-0.34 \pm 1.68$ \\
\hline $\begin{array}{l}\text { Lymphocyte count, } \\
10^{3} \text { cells } / \mathrm{mm}^{3}\end{array}$ & $-0.01 \pm 0.50$ & $-0.03 \pm 0.66$ & $0.10 \pm 0.61$ & $-0.17 \pm 0.54$ & $0.10 \pm 0.69$ & $-0.23 \pm 0.72$ & $-0.43 \pm 0.58$ & $-0.06 \pm 0.61$ & $0.03 \pm 0.50$ & $-0.02 \pm 0.59$ \\
\hline ALT, IU/1 & $2.2 \pm 14.6$ & $2.5 \pm 12.7$ & $2.8 \pm 23.0$ & $4.8 \pm 36.4$ & $-1.3 \pm 8.4$ & $5.1 \pm 15.7$ & $83.4 \pm 466.7$ & $-0.7 \pm 19.0$ & $3.0 \pm 19.8$ & $-7.7 \pm 16.5$ \\
\hline HDL-C, $\mathrm{mg} / \mathrm{dl}$ & $3.5 \pm 10.0$ & $5.7 \pm 12.6$ & $10.0 \pm 11.5$ & $-1.4 \pm 10.4$ & $0.4 \pm 12.4$ & $-0.1 \pm 15.1$ & $-3.7 \pm 15.3$ & $1.4 \pm 9.4$ & $1.0 \pm 13.7$ & $0.2 \pm 11.7$ \\
\hline LDL-C, mg/dl & $11.5 \pm 22.8$ & $8.8 \pm 32.6$ & $14.0 \pm 30.9$ & $5 \pm 27$ & $-2 \pm 19$ & $7 \pm 29$ & $4 \pm 35$ & $-4 \pm 34$ & $5 \pm 36$ & $-1 \pm 26$ \\
\hline Creatinine, $\mathrm{mg} / \mathrm{dl}$ & $0.04 \pm 0.10$ & $0.05 \pm 0.08$ & $0.07 \pm 0.13$ & $0.001 \pm 0.115$ & $-0.006 \pm 0.093$ & $-0.010 \pm 0.119$ & $-0.008 \pm 0.120$ & $0.000 \pm 0.081$ & $0.000 \pm 0.104$ & $-0.016 \pm 0.078$ \\
\hline
\end{tabular}

4/4 mg = $4 \mathrm{mg}$ baricitinib through Week 128. 4:8/4 = $4 \mathrm{mg}$ baricitinib through Week 28 or 32 then $8 \mathrm{mg}$ through Week 76 and $4 \mathrm{mg}$ for weeks 76-128. 8/4 mg $=8 \mathrm{mg}$ baricitinib through Week 76 and $4 \mathrm{mg}$ for weeks 76-128. " $\mathrm{n}$ " mean no. patients treated with stated dose regimen in the study period. Pre-rescue includes all laboratory results obtained prior to dose escalation. Post-rescue includes all laboratory results obtained after dose escalation. *For patients with dose escalation, the value obtained at the dose escalation visit is used instead of baseline at Week 24 for the post-rescue time period. ALT: alanine aminotransferase; HDL-C: high-density lipoprotein cholesterol; LDL-C: low-density lipoprotein cholesterol; OLE: open-label extension.

blinded period and no clear pattern of change was observed during the second OLE. High-density lipoprotein cholesterol did not change by a clinically meaningful amount during either OLE. Changes through both OLE in mean creatinine and CPK were considered clinically insignificant.

Clinical efficacy. In the 24-week blinded period, significantly more patients in the combined baricitinib 4- and 8-mg groups compared to placebo achieved the primary endpoint of an ACR20 response at Week $12^{5}$. The proportions of patients achieving an ACR20, ACR50, or ACR70 response at Week 24 of the double-blind period were maintained through Week 76 and Week 128 of the OLE (Table 5). When measured at weeks 24,76 , and 128 , the percentages of patients who achieved DAS28-CRP and DAS28-ESR scores $\leq 3.2$ and $<2.6$ were also maintained during the OLE, with similar consistency over time seen for remission rates as measured by ACR/EULAR (Boolean definition), CDAI $(\leq 2.8)$, or SDAI ( $\leq 3.3$; Table 5). Improvement in HAQ-DI was 
Table 4. Changes in laboratory results (patients who worsened to that grade from baseline). Data are $\mathrm{n}(\%)$ and indicate no. patients treated with stated dose regimen in the study period.

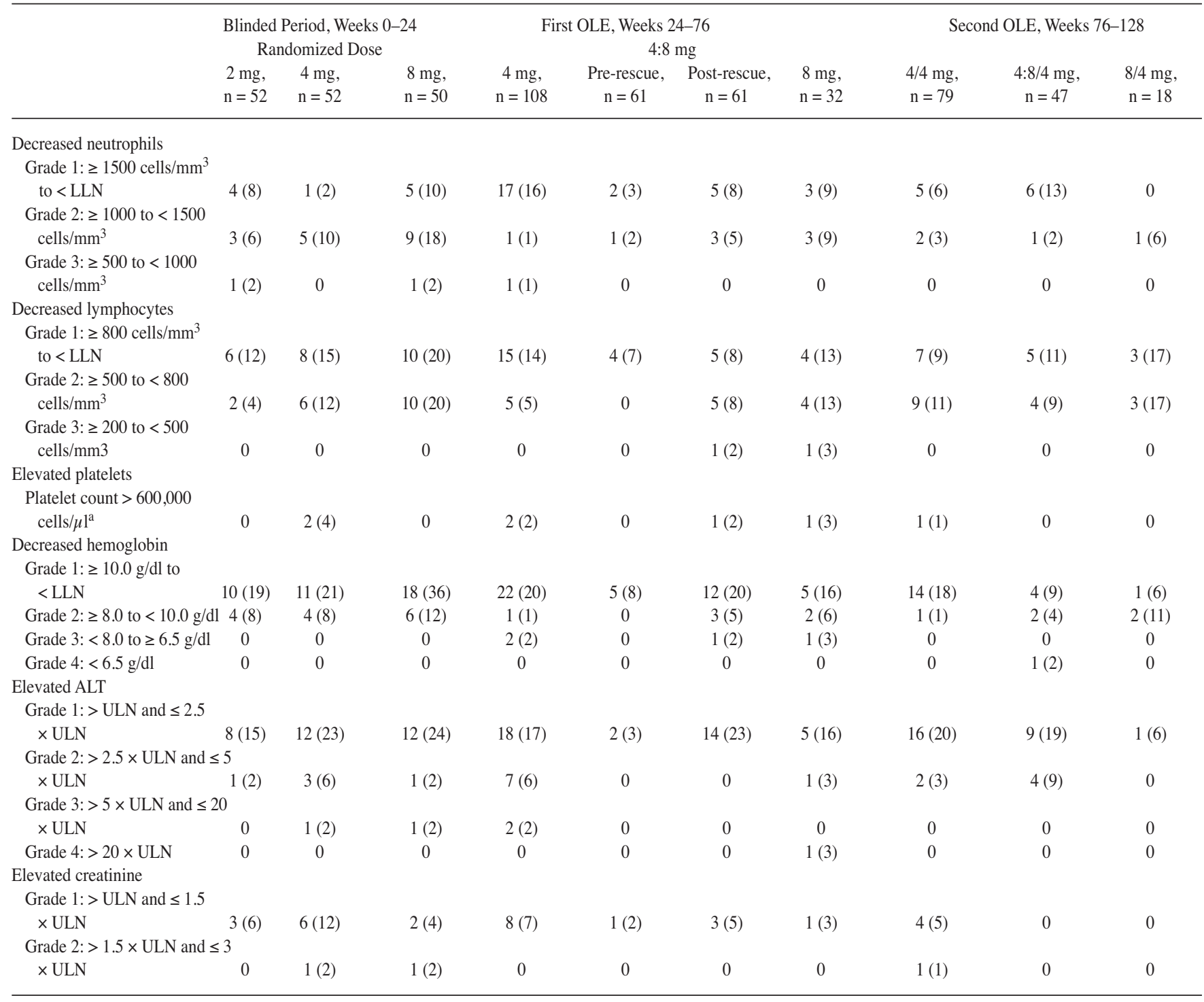

Baseline in the blinded period is Week 0, baseline in the first OLE is Week 24, and baseline in the second OLE is Week 76. Laboratory grades defined using Common Terminology Criteria for Adverse Events, version 4.0.4/4 mg = $4 \mathrm{mg}$ baricitinib through Week 128. 4:8/4 = $4 \mathrm{mg}$ baricitinib through Week 28 or 32 , then $8 \mathrm{mg}$ through Week 76 and $4 \mathrm{mg}$ for weeks $76-128.8 / 4 \mathrm{mg}=8 \mathrm{mg}$ baricitinib through Week 76 and $4 \mathrm{mg}$ for weeks $76-128$. Pre-rescue includes all abnormalities that occurred on or before the

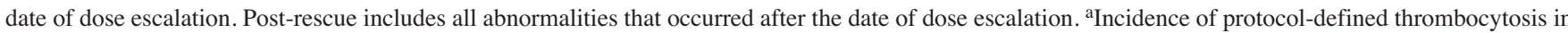
patients with platelet counts > 600,000 cells $/ \mu 1$. ALT: alanine aminotransferase; LLN: lower limit of normal; OLE: open-label extension; ULN: upper limit of normal.

similarly maintained (Table 5). During the first OLE, some efficacy measures showed improvement at Week 76 compared to Week 24 in the group of patients who increased dose from $4 \mathrm{mg}$ to $8 \mathrm{mg}$ QD at weeks 28 or 32 (Supplementary Figures 3 and 4, available with the online version of this article). The dose-escalation option was used more often in patients who had received doses of baricitinib lower than 4 mg QD during a portion of the 24-week blinded period; improvements in response after dose escalation in the first OLE appeared largely confined to these patients, whereas patients originally randomized to the 4-mg QD dose did not exhibit improved disease activity after this open-label, nonrandomized dose-escalation $\operatorname{step}^{6}$ (data not shown). In the second OLE, the improvement in efficacy measures observed at the end of the first OLE (Week 76) was generally maintained through 128 weeks regardless of dose (Supplementary Figures 3 and 4, available with the online version of this article). In the very small subset of patients entering the second OLE and having been originally randomized to baricitinib $8 \mathrm{mg}$, an increase in disease activity was observed for

Personal non-commercial use only. The Journal of Rheumatology Copyright @) 2018. All rights reserved. 
Table 5. The proportions of patients achieving selected efficacy endpoints at Week 24, Week 76, and Week 128. Values are n (\%).

\begin{tabular}{|c|c|c|c|c|c|c|c|c|c|}
\hline & $\begin{array}{c}4 \mathrm{mg}, \\
\mathrm{n}=108\end{array}$ & $\begin{array}{c}\text { Week } 24^{\mathrm{a}} \\
4: 8 \mathrm{mg} \\
\mathrm{n}=61\end{array}$ & $\begin{array}{l}8 \mathrm{mg}, \\
\mathrm{n}=32\end{array}$ & $\begin{array}{c}4 \mathrm{mg}, \\
\mathrm{n}=108\end{array}$ & $\begin{array}{c}\text { Week } 76^{\mathrm{b}} \\
4: 8 \mathrm{mg} \\
\mathrm{n}=61\end{array}$ & $\begin{array}{l}8 \mathrm{mg}, \\
\mathrm{n}=32\end{array}$ & $\begin{array}{c}4 / 4 \mathrm{mg} \\
\mathrm{n}=79\end{array}$ & $\begin{array}{c}\text { Week } 128^{c} \\
4: 8 / 4 \mathrm{mg} \\
\mathrm{n}=47\end{array}$ & $\begin{array}{c}8 / 4 \mathrm{mg} \\
\mathrm{n}=18\end{array}$ \\
\hline ACR20 & $87(81)$ & $38(62)$ & $24(75)$ & $77(71)$ & $41(67)$ & $19(59)$ & $61(77)$ & $27(57)$ & $13(72)$ \\
\hline ACR50 & $53(49)$ & $12(20)$ & $18(56)$ & $53(49)$ & $25(41)$ & $14(44)$ & $46(58)$ & $14(30)$ & $8(44)$ \\
\hline ACR70 & $29(27)$ & $5(8)$ & $9(28)$ & $31(29)$ & $11(18)$ & $8(25)$ & $22(28)$ & $8(17)$ & $4(22)$ \\
\hline \multicolumn{10}{|c|}{ ACR/EULAR Boolean } \\
\hline HAQ-DI ${ }^{\mathrm{d}}$ & $47(44)$ & $25(41)$ & $22(69)$ & $55(51)$ & $29(48)$ & $22(69)$ & $39(49)$ & $19(40)$ & $10(56)$ \\
\hline DAS28-CRP $\leq 3.2$ & $64(59)$ & $15(25)$ & $18(56)$ & $63(58)$ & $23(38)$ & $14(44)$ & $47(59)$ & $17(36)$ & $10(56)$ \\
\hline DAS28-CRP $<2.6$ & $43(40)$ & $5(8)$ & $13(41)$ & $56(52)$ & $13(21)$ & $7(22)$ & $37(47)$ & $12(26)$ & $7(39)$ \\
\hline DAS28-ESR $\leq 3.2$ & $38(35)$ & $5(8)$ & $12(38)$ & $45(42)$ & $15(25)$ & $9(28)$ & $39(49)$ & $12(26)$ & $5(28)$ \\
\hline DAS28-ESR $<2.6$ & $27(25)$ & $1(2)$ & $7(22)$ & $30(28)$ & $10(16)$ & $4(13)$ & $27(34)$ & $6(13)$ & $4(22)$ \\
\hline $\mathrm{CDAI} \leq 2.8$ & $24(22)$ & $1(2)$ & $9(28)$ & $27(25)$ & $6(10)$ & $5(16)$ & $22(28)$ & $5(11)$ & $4(22)$ \\
\hline $\mathrm{SDAI} \leq 3.3$ & $24(22)$ & $1(2)$ & $7(22)$ & $27(25)$ & $6(10)$ & $5(16)$ & $23(29)$ & $3(6)$ & $4(22)$ \\
\hline
\end{tabular}

$4 / 4 \mathrm{mg}=4 \mathrm{mg}$ baricitinib for weeks 24-76 and weeks 76-128. 4:8/4 = $4 \mathrm{mg}$ baricitinib through Week 28 or 32, then $8 \mathrm{mg}$ through Week 76 and $4 \mathrm{mg}$ for weeks 76-128. 8/4 mg = $8 \mathrm{mg}$ baricitinib for weeks $24-76$ and $4 \mathrm{mg}$ for weeks $76-128$. ${ }^{\mathrm{a}}$ Observed data for patients entering OLE at Week 24 according to the treatment(s) received in the first OLE. ${ }^{b}$ Nonresponse imputed for discontinuing prior to Week 76 , but not for dose escalation. ${ }^{\mathrm{c}}$ Among patients entering additional OLE, nonresponse imputed for discontinuing prior to Week 128. ${ }^{\mathrm{d}}$ Patients achieving minimum clinically important difference ( $\left.\geq 0.3\right)$ : improvement relative to Week 0. ACR: American College of Rheumatology; ACR20: ACR 20\% improvement; ACR50: ACR 50\% improvement; ACR70: ACR 70\% improvement; CDAI: Clinical Disease Activity Index; DAS28-CRP: Disease Activity Score for 28 joints based on the C-reactive protein level; DAS28-ESR: DAS28 based on the erythrocyte sedimentation rate; EULAR: European League Against Rheumatism; HAQ-DI: Health Assessment Questionnaire-Disability Index; OLE: open-label extension; SDAI: Simplified Disease Activity Index.

some measures (for example, CDAI) after the dose was reduced to $4 \mathrm{mg}$ (Supplementary Figures 3 and 4, available with the online version of this article). However, with the small size of this group and the possibility for open-label expectation bias, this observation should be viewed with caution. The results from the randomized, double-blind, placebo-controlled period suggest there was no incremental clinical benefit in patients receiving $8 \mathrm{mg}$ versus $4 \mathrm{mg}$ of baricitinib.

\section{DISCUSSION}

The safety and tolerability profile of baricitinib through the 104-week OLE period of this phase IIb study was generally consistent with prior observations gathered during shorter durations of exposure ${ }^{3,4,5}$. Few patients experienced AE leading to discontinuation, and $\mathrm{AE}$ rates including infection stabilized or diminished with prolonged treatment. Event types such as malignancies or opportunistic infections did not emerge with prolonged treatment. Herpes zoster infections were reported without evidence of a dose effect during the OLE period at incidence rates (2.3/100 patient-yrs) similar to those described in association with biologic DMARD in $\mathrm{RA}^{7,8}$. Laboratory abnormalities leading to discontinuation were uncommon. There was no evidence of progressive worsening over time or after extended dosing. The frequency of any grade of elevated ALT or creatinine or decreased hemoglobin, neutrophils, or lymphocytes was stable during the OLE period. Evaluation of larger integrated safety datasets that incorporate longterm data including those generated in phase III studies will elucidate the longterm benefit/risk profile of baricitinib in RA with more clarity 9 .
Baricitinib treatment resulted in significant improvement compared to placebo over the initial 12 weeks, with responses maintained or improved in all measures through 24 weeks ${ }^{6}$. In the present report, NRI and LOCF were applied during both the blinded and open-label study phases for efficacy measures to patients who discontinued prematurely. Maintenance or improvement of efficacy response was seen from 24 through 76 weeks of treatment and was sustained in the second OLE period from 76 through 128 weeks of treatment.

There are a number of study limitations to consider in evaluating the present data, some of which are common to many OLE studies. A comparator group (placebo or active) was not included in the extension phase. Participation in the OLE was optional, and patients' experience of benefit/risk in the earlier double-blind period may well have influenced their decision to proceed to the OLE. In addition, the sample size was subject to the inherent restrictions of phase II development. Despite these limitations, during up to 2.5 years of treatment, once-daily oral baricitinib produced sustained efficacy in RA across a variety of accepted categorical efficacy measures, analyzed using NRI. The safety and tolerability profile remained consistent with earlier observations, and unexpected late signals did not emerge. These data support the potential utility of baricitinib as a valuable additional therapy for the treatment of this common and disabling disease.

Baricitinib, an oral inhibitor of JAK1 and JAK2, has demonstrated significant improvement in disease activity versus placebo, with an acceptable safety profile after 24

Personal non-commercial use only. The Journal of Rheumatology Copyright $\odot$ (2018. All rights reserved 
weeks of treatment for patients with established RA and an inadequate response to MTX. In this phase IIb study, safety data collected during 2 subsequent years of OLE were generally consistent with previous findings for baricitinib in RA. With prolonged treatment, rates of AE and laboratory abnormalities did not increase, and important new event types such as opportunistic infections or malignancies did not emerge. Clinical improvement observed at Week 24 was maintained or improved through Week 128.

\section{ACKNOWLEDGMENT}

The authors thank Victoria L. Crotzer, PhD, of Eli Lilly and Company, for her creation of the tables and figures and for her assistance with manuscript preparation and process support, and Kathy Oneacre, of inVentiv Health Clinical, for her assistance with manuscript preparation and process support.

\section{ONLINE SUPPLEMENT}

Supplementary material accompanies the online version of this article.

\section{REFERENCES}

1. O'Shea JJ, Kontzias A, Yamaoka K, Tanaka Y, Laurence A. Janus kinase inhibitors in autoimmune diseases. Ann Rheum Dis 2013;72 Suppl 2:ii111-5.

2. Fridman JS, Scherle PA, Collins R, Burn TC, Li Y, Li J, et al. Selective inhibition of JAK1 and JAK2 is efficacious in rodent models of arthritis: preclinical characterization of INCB028050. J Immunol 2010;184:5298-307.
3. Greenwald MW, Fidelus-Gort R, Levy R, Liang J, Vaddi K, Williams WV, et al. A randomized dose-ranging, placebo-controlled study of INCB028050, a selective JAK1 and JAK2 inhibitor in subjects with active rheumatoid arthritis [abstract]. Arthritis Rheum 2010;62 Suppl 10:S911.

4. Tanaka Y, Emoto K, Cai Z, Aoki T, Schlichting D, Rooney T, et al. Efficacy and safety of baricitinib in Japanese patients with active rheumatoid arthritis receiving background methotrexate therapy: a 12-week, double-blind, randomized placebo-controlled study. J Rheumatol 2016;43:504-11.

5. Keystone EC, Taylor PC, Drescher E, Schlichting DE, Beattie SD, Berclaz PY, et al. Safety and efficacy of baricitinib at 24 weeks in patients with rheumatoid arthritis who have had an inadequate response to methotrexate. Ann Rheum Dis 2015;74:333-40.

6. Taylor P, Genovese MC, Keystone E, Schlichting D, Beattie S, Macias W. Baricitinib, an oral janus kinase inhibitor, in the treatment of rheumatoid arthritis: safety and efficacy in open-label, long-term extension study [abstract]. Ann Rheum Dis 2013;72 Suppl 3:A65-6.

7. Winthrop KL, Yamanaka H, Valdez H, Mortensen E, Chew R, Krishnaswami S, et al. Herpes zoster and tofacitinib therapy in patients with rheumatoid arthritis. Arthritis Rheum 2014; 66:2675-84

8. Yun H, Xie F, Delzell E, Chen L, Levitan EB, Lewis JD, et al. Risks of herpes zoster in patients with rheumatoid arthritis according to biologic disease-modifying therapy. Arthritis Care Res 2015;67:731-6.

9. Smolen J, Genovese M, Takeuchi T, Hyslop D, Macias WL, Rooney TP, et al. Safety profile of baricitinib in patients with active RA: an integrated analysis [abstract]. Ann Rheum Dis 2016;75 Supp1 2:243-4. 